\title{
A new blast-mitigation solution for building facade protection with a laminated polycarbonate based system
}

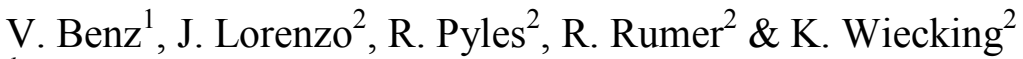 \\ ${ }^{1}$ Bayer MaterialScience GmbH, Germany \\ ${ }^{2}$ Bayer MaterialScience LLC, USA
}

\begin{abstract}
An innovative polycarbonate-based blast-mitigating system has been developed and shown to offer building protection from air-borne pressure waves produced by a blast event. The system can be tailored to protect against a range of threat levels. The system, containing a high-tech polycarbonate laminate, can protect building exteriors as well as provide a decorative appearance. It can be adapted to existing (retrofit) and new buildings as well. To simulate a vehicle-borne improvised explosive device (VBIED), open-arena blast testing has demonstrated the capabilities of this system to protect a masonry wall from significant blast pressures. Advanced modelling has been conducted to predict the system performance. The benefits of a blast mitigating façade are discussed within the scope of open-arena blast tests and an outlook toward future applications is given.

Keywords: blast mitigation, polycarbonate laminate, building facade protection, Hygard $^{\circledR} B L 80$.
\end{abstract}

\section{Introduction}

With ever-increasing threats and always-decreasing budgets, a new innovative blast-mitigating system for critical buildings and structures has been developed which can be added to existing buildings to avoid the high costs of relocating or re-building hardened structures. The system combines the aesthetics and impact resistance of polycarbonate panels with a high strength, energy-absorbing steel mounting structure. The system now allows most buildings to be upgraded to higher blast protection levels than previously available. In particular, the system 
is ideal for buildings in urban settings where standoff distance is greatly diminished.

While polycarbonate has been used in architectural glazing applications for years providing moderate blast protection and ballistics resistance, new material and coating developments have pushed the envelope thus allowing its use in blast applications which significantly exceed published threat levels.

\section{System description}

The system shown in fig. 1 is an artist's rendering, which is designed to either completely encapsulate an existing building, including the roof surfaces, or can be implemented on portions of a building to protect vulnerable areas.

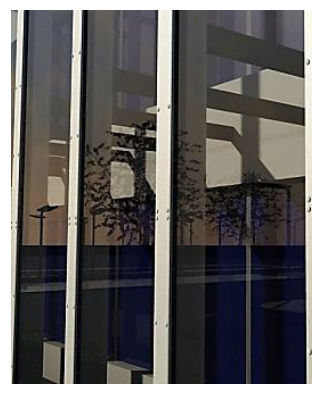

Figure 1: $\quad$ Polycarbonate blast-mitigating system retro-fit.

The system is made of vertical steel columns set in a concrete foundation which support the polycarbonate panels providing either a transparent or decorative surface. Also noted in fig. 1 is the absence of horizontal structural members, thus providing additional day-lighting.

Fig. 2 shows a view from within the gap space between the protective structure and the existing building. Lateral struts are placed between the vertical

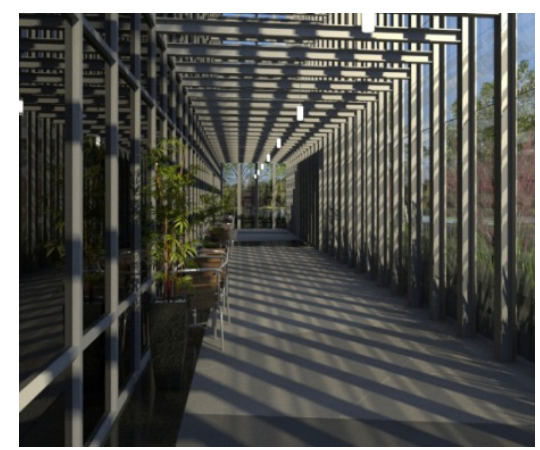

Figure 2: Interior view of polycarbonate blast-mitigating system retro-fit. 
columns and existing building as a means of transmitting lateral blast forces to the floor slabs.

The system utilizes bolted connections of the polycarbonate panels to the columns as shown in a cross-sectional view in fig. 3, and is designed to mitigate blast pressures and impulses as high as 80 psi. (550 kPa) and 380 psi-msec. (2620 kPa-msec.), respectively. The system can be easily scaled up or down to match unique performance requirements.

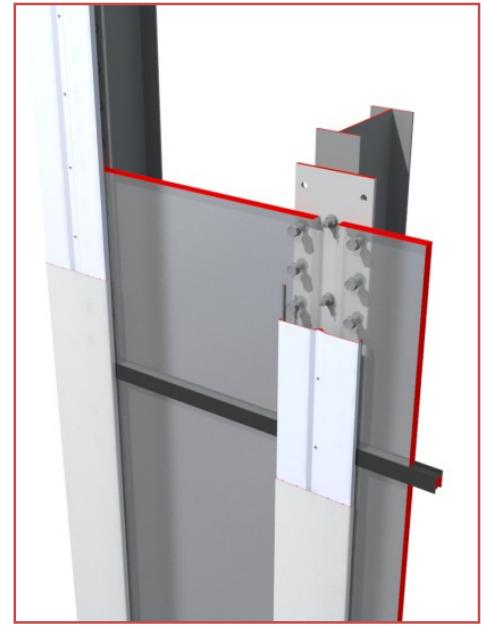

Figure 3: Cross-sectional view of polycarbonate blast-mitigating system.

\section{System validation}

To demonstrate the system's viability, an open-arena test utilizing live explosives was conducted at the Energetic Materials and Research Test Center (EMRTC) in New Mexico and shown in fig. 4. The system was erected to protect two 4 inch $(100 \mathrm{~mm})$ thick, lightly-reinforced concrete panels and 2-story multi-bay building at EMRTC. The 14 foot $(4.3 \mathrm{~m})$ tall, 20 foot $(6.1 \mathrm{~m})$ wide, 7 foot $(2.1 \mathrm{~m})$ deep system included three sides and roof to test the full system. The front surface used five, 4 foot wide by 8 foot tall polycarbonate panels along the bottom, and five, 4 foot by 6 foot panels along the top. The protective polycarbonate system was offset 7 feet $(2.1 \mathrm{~m})$ from the protected concrete wall. A third concrete wall panel was used as a control and left un-protected at the same standoff as the protected concrete wall.

The charge type, mass and standoff distance were selected to produce the desired design pressure and impulse. Figure 5 shows an image taken during the test.

The test structure was instrumented with piezoelectric pressure transducers at various locations to record pressure-time histories developed during the blast event as shown in fig. 6. To determine the pressure drop resulting from the system, pressure transducers were located on both sides of the polycarbonate 


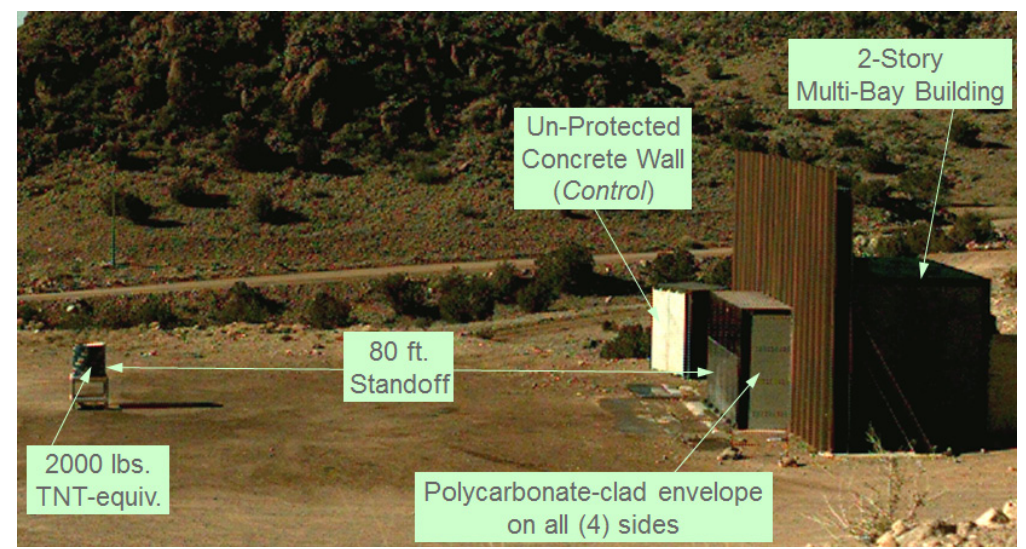

Figure 4: Open arena test of the blast-mitigating system.

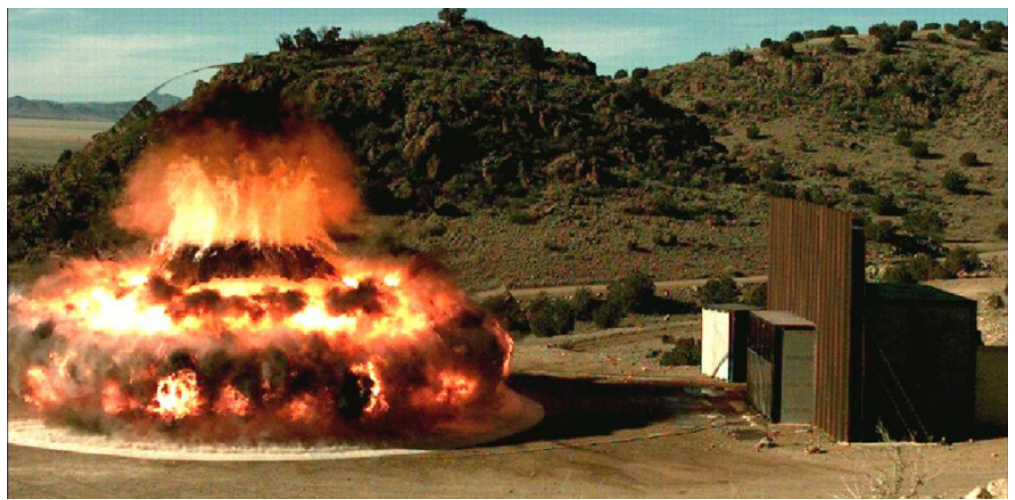

Figure 5: Image from open arena testing of the blast-mitigating system.

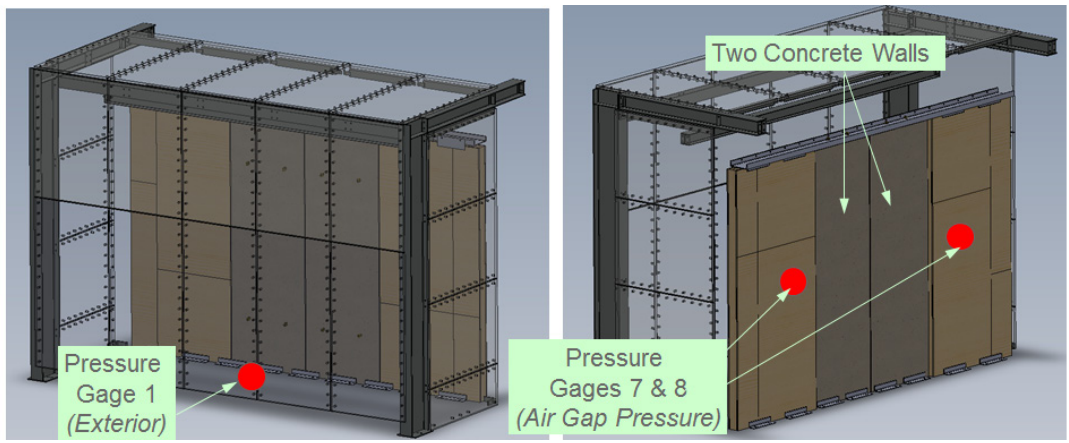

Figure 6: Open-arena test instrumentation. 
panel. Gage 1 was located at ground level and on the exterior of the system to record the maximum pressure history. Gages 7 and 8 were located in the gap to measure the remaining pressure record at the building wall.

A laser deflection sensor was also included in the gap space to measure the polycarbonate panel deflection during the test.

\subsection{Test results}

The results from the blast test were highly successful. The maximum pressure recorded was $130 \mathrm{psi}(890 \mathrm{kPa})$ which greatly exceeded the design pressure by nearly 70\%. The maximum recorded impulse was 333 psi-msec. (2290 kPamsec.) which was lower than the design impulse of 380 psi-msec. (2620 kPamsec.) by $12 \%$.

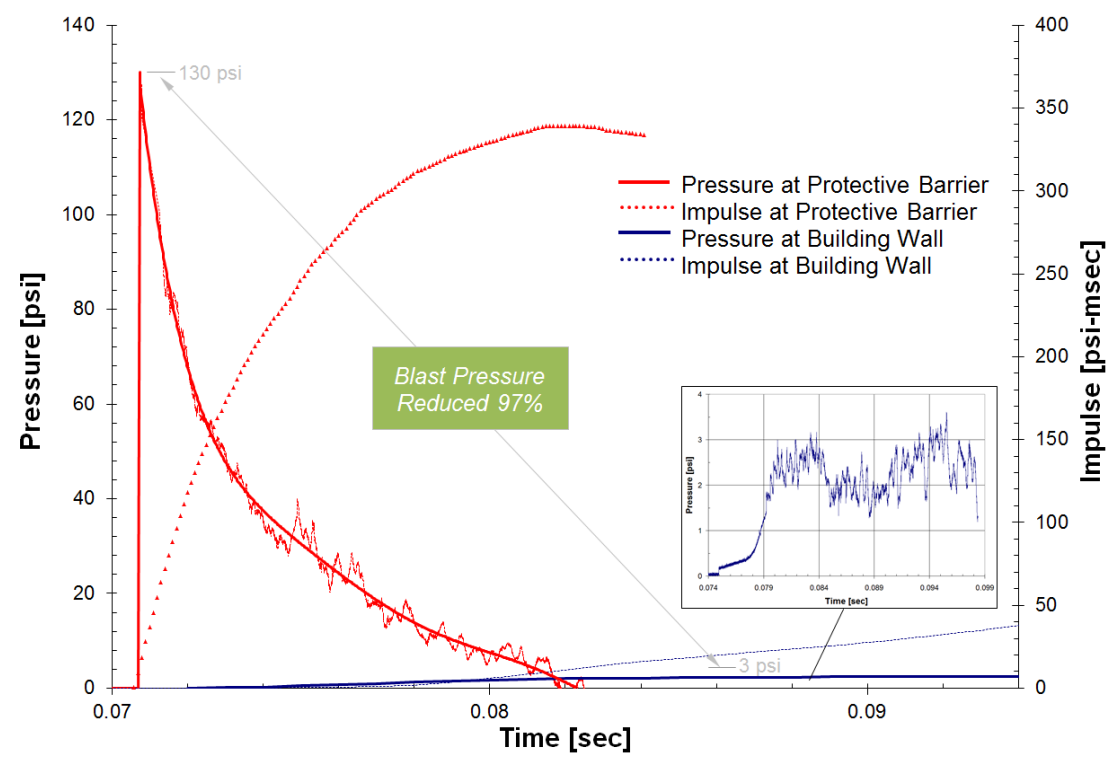

Figure 7: $\quad$ Pressure and impulse histories recorded in the open-arena test.

The recorded pressure and impulse time histories for gage 1 are plotted in fig. 7. Also plotted are the pressure and impulse time histories inside the gap next to the protected concrete panels. The peak pressure measured in the gap was 3 psi $(0.02 \mathrm{kPa})$ and an impulse of 46 psi-msec. $(0.32 \mathrm{kPa}-\mathrm{msec})$.

The post-test image of the system shown in fig. 8 is indicative of low damage sustained from the blast test. All polycarbonate panels remained intact and attached to the steel structure. Only minor permanent deformation was seen in the panels and vertical steel columns. Also evident is the complete destruction of the unprotected concrete pre-cast panel lying on the ground. 


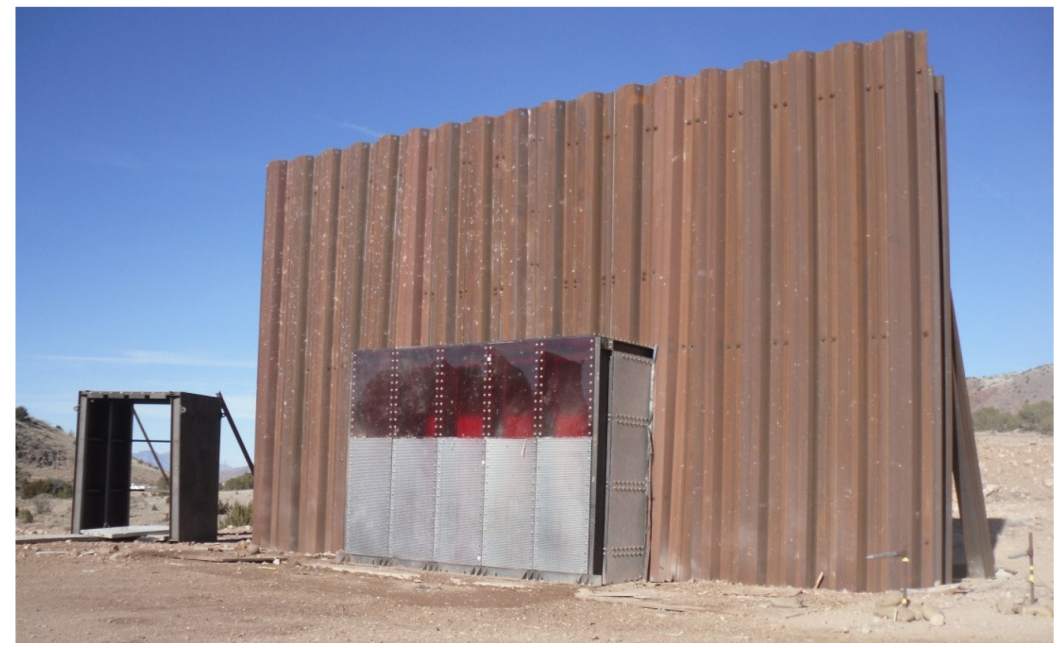

Figure 8: $\quad$ Post-test image showing system intact.

In contrast, the protected pre-cast concrete panels shown in fig. 9 sustained only minor surface cracks, highlighted by a black marker pen to enhance visibility for the photo.

Additional shock-tube testing and simulation modelling has been carried by Kenady et al. [1], investigating the effects of the pressure-rise developed in the gap space resulting from the polycarbonate deflection into the enclosed volume of air between the panels and building wall. This research is critical in understanding the gap space sizing relative to a specific threat level. Finite element analysis techniques were also investigated for accurate means of predicting the pressure-rise that must be borne by the building.

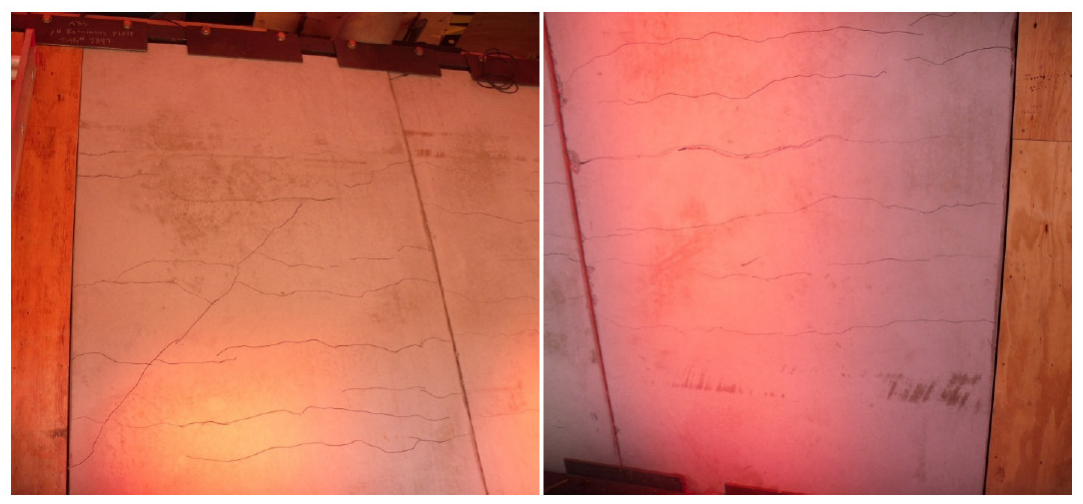

Figure 9: Post-test image of minor surface cracks in protected concrete panels. 


\section{Advanced modelling for full-scale building assessment}

After the successful live blast test of the system on a mock building, the system was then analyzed on a full-scale 5-story commercial building utilized FACET3D, a software code developed and utilized by ABS Consulting for damage and risk assessment. Results from the open-arena and previous shocktube testing of the system allowed for the development of pressure-impulse diagrams that are used as input to the FACET3D code.

\subsection{Full-scale building description}

A typical 5-story commercial building shown in fig. 10 was used to examine the performance of the system retro-fit to the exterior walls and roof. The construction was assumed to be reinforced concrete frame with metal cladding at the spandrel. Seventy percent of the exterior is covered with glass fenestration. The building also includes a concrete joist-slab roof.

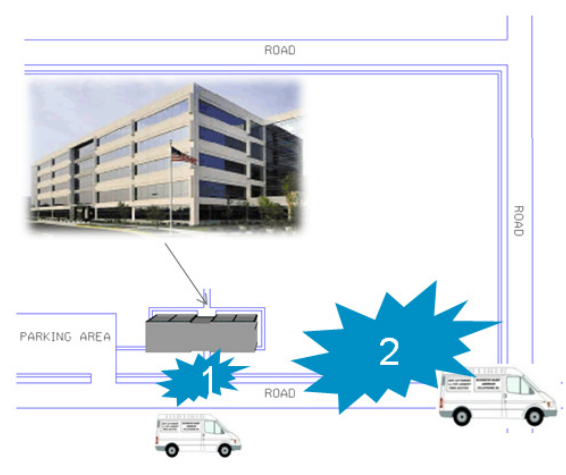

Figure 10: Full-scale building and plan view of threat scenarios.

The building is set in an urban environment with short standoff distances to nearby streets. Two different threat scenarios were considered where the building is assessed for damage both with and without the protective polycarbonate system installed.

\subsection{Full-scale building assessment for threat scenario 1}

In the first threat scenario, a $2000 \mathrm{lbs}$ TNT charge with an $80 \mathrm{ft}$. standoff from the front of the building is considered. The predicted damage is high for the facade sides and glazing in the unprotected version as described in fig. 11. Here, roof collapse and glass hazards are expected for the front and sides. A high likelihood for occupant fatalities and injuries from airborne glass debris is expected. 


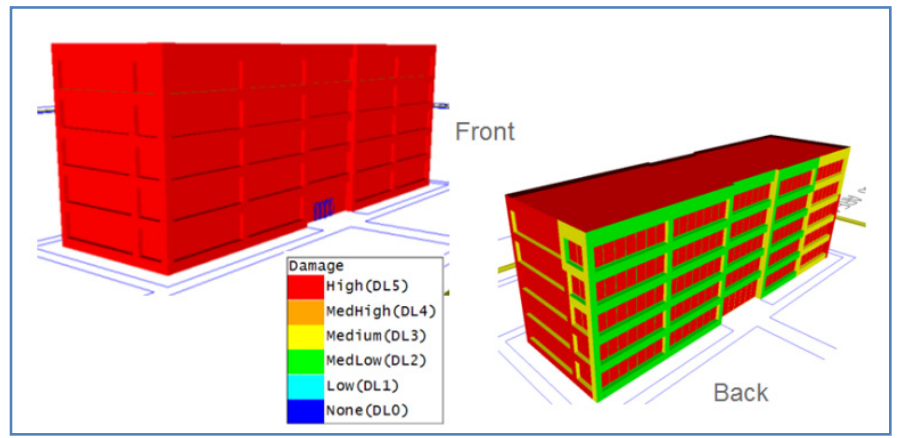

Figure 11: Damage predicted in un-protected building, threat scenario \#1.

With the building encapsulated on the front, sides and roof with the polycarbonate protective system, the predicted damage to these surfaces are extremely low, as shown in fig. 12. A large portion of the back side was left unprotected due the lower pressures and impulse expected in this area. The system is predicted to dramatically reduce the damage to the façade, glazing and roof to minimal.

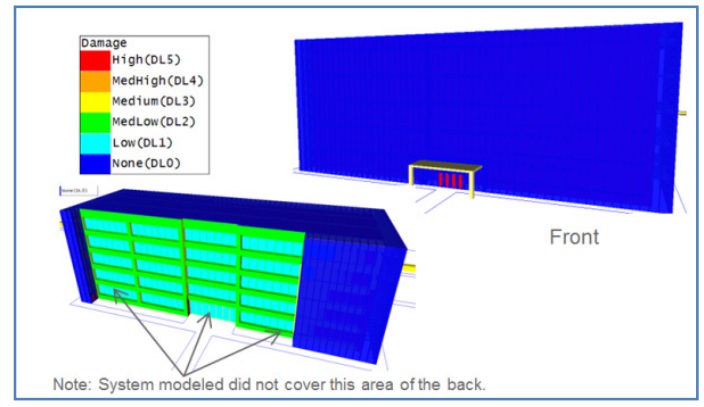

Figure 12: $\quad$ Damage predicted in protected building, threat scenario \#1.

\subsection{Full-scale building assessment for threat scenario 2}

In the second threat scenario, a 10,000 lbs TNT charge with a $250 \mathrm{ft}$. standoff from the front corner of the building is considered. The predicted damage is high for the facade sides and glazing in the unprotected version as described in fig. 13. Here too, roof collapse and glass hazards are expected for the front and sides. Similar to the previous case, a high likelihood for occupant fatalities and injuries from airborne glass debris is expected. 


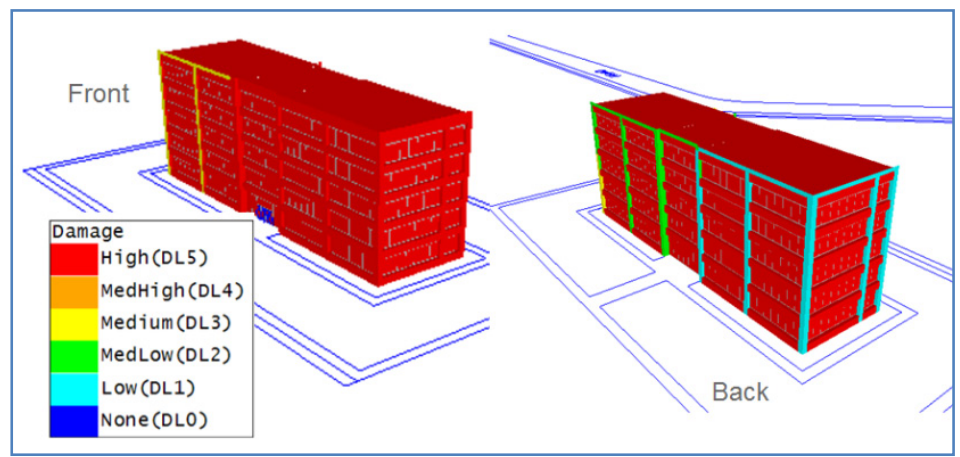

Figure 13: $\quad$ Damage predicted in un-protected building, threat scenario \#2.

With the building protection, the predicted damage to these surfaces is extremely low, as shown in fig. 14. The system is predicted to dramatically reduce the damage to the façade, glazing and roof to minimal.

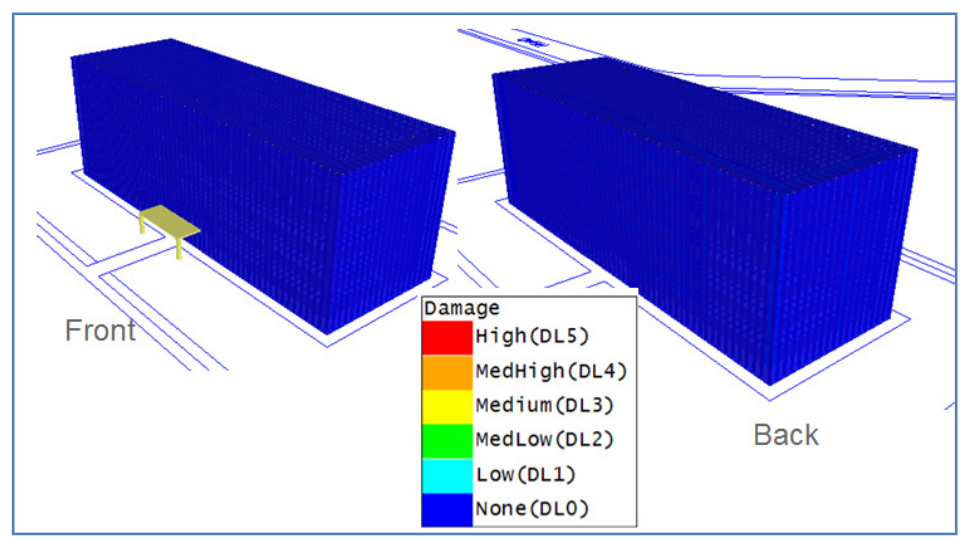

Figure 14: $\quad$ Damage predicted in protected building, threat scenario \#2.

Additional modelling has been conducted using finite element analysis tools to predict system performance. The finite element simulation enabled a broad range of threat levels to be evaluated from which a frontier map, as shown in fig. 15 could be developed. The blue shaded region above the dark blue curve is the expected zone of protection. The simulation model includes two confirming data points from actual open-arena testing of the system. 


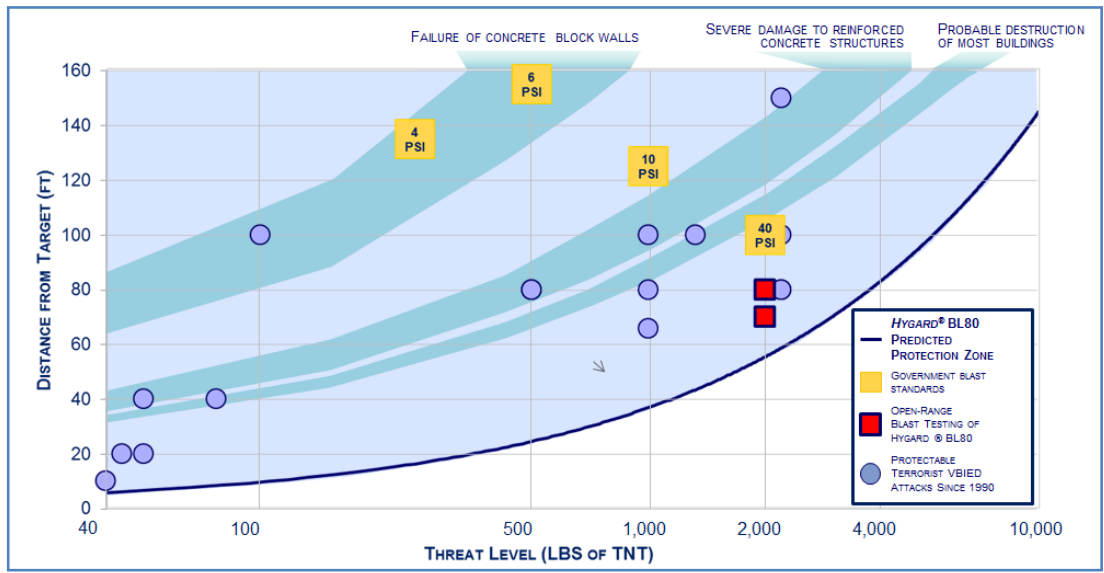

Figure 15: Range of protection predicted for the polycarbonate protective system.

\section{Annual building energy consumption analysis}

As a secondary skin added to the exterior of building, the protective polycarbonate system acts as a dual wall façade which provides natural convective cooling up the faces of the building and vents through small openings in the roof.

To evaluate the impact of the protective system on the building energy consumption, a modelling simulation study was conducted by $\mathrm{CH} 2 \mathrm{M}$ Hill, using Integrated Environmental Solutions - Virtual Environment (IES-VE) software. The same full-scale building, set in the Washington D.C. climate, was modelled as shown in fig. 16, and compared both with and without the protective system.

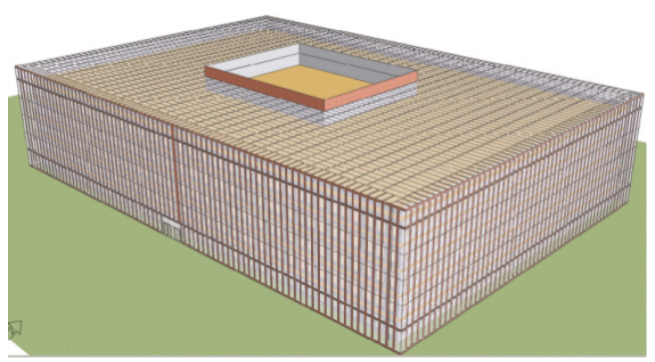

Figure 16: Building model with polycarbonate system.

Assumptions for the thermal and insulation properties of the various building elements used in the simulation for both cases are provided in Table 1. 
Table 1: $\quad$ Model assumptions used for building energy calculations.

\begin{tabular}{|c|c|c|}
\hline Building elements & Baseline & $\begin{array}{l}\text { With polycarbonate system } \\
\text { deployed }\end{array}$ \\
\hline Building skin - Wall (U - Btu/h.ft F) & $0.06 / \mathrm{R} 15$ & $0.06 / \mathrm{R} 15$ \\
\hline $\begin{array}{l}\text { Building skin - Glass } \\
\text { (U - Btu/h.ft F / SC) }\end{array}$ & $1.22 / 0.21^{1}$ & $0.48 / 0.28$ \\
\hline $\begin{array}{c}\text { Structural Envelope } \\
\text { Steel Columns (U - Btu/h.ft F) }\end{array}$ & N/A & 0.492 / R-1.06 - Steel Columns \\
\hline Structural Envelope (U - Btu/h.ft F) & N/A & $\begin{array}{c}0.443 / \mathrm{SC}=0.87^{2} \\
\text { Visible Transmittance }=0.76\end{array}$ \\
\hline $\begin{array}{c}\text { Building Roof - Existing } \\
\text { (U - Btu/h.ft F) }\end{array}$ & 0.044 / R22 & 0.044 / R22 \\
\hline $\begin{array}{c}\text { Structural Envelope Roof - New } \\
\text { (Polycarbonate sheet - U - Btu/h.ft F) }\end{array}$ & $\mathrm{N} / \mathrm{A}$ & $\begin{array}{c}0.447 \text { / } \mathrm{SC}=0.06 ; \\
\text { Light transmission: } 5 \% \\
\text { Reflectance: } 81.8 \%\end{array}$ \\
\hline Cavity Beams (U - Btu/h.ft $\stackrel{2}{\mathrm{~F}})$ & N/A & 0.35 / R-2.0 \\
\hline
\end{tabular}

1 - Single Pane glass based on ASHRAE climate zone.

2 - A value of 1.0 indicates no shading effect, while a value of 0 indicates a total (complete) shading effect (no solar radiation load).

3 - Based on use of BAYBLOCK ${ }^{\mathrm{TM}}$ HT/HT BASE water-resistant protective coating.

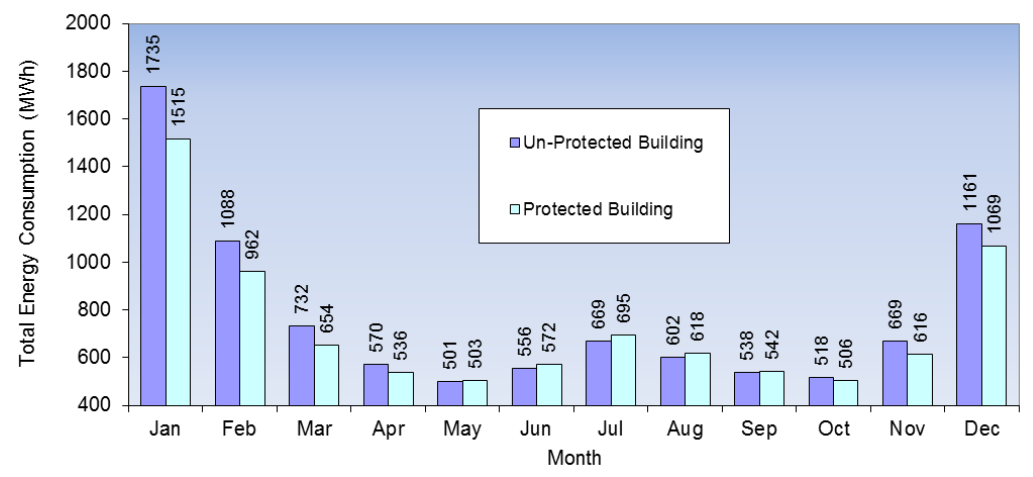

Figure 17: Annual total building energy consumption comparison for Washington, DC climate.

Results on a month-by-month basis are shown in fig. 17 for both the protected and un-protected building. The protected system without opening or gaps for ingress into the gap space between the system and building provided enough energy savings in the colder months to offset the negative savings during the summer months. The annual savings is predicted to be $3.5 \%$ when comparing 
the total building energy consumption (i.e. boilers, chillers, pumps, fans, lighting, etc). Table 2 provides simulations results for additional climate extremes.

Table 2: $\quad$ Predicted reduction in total building annual energy consumption from installation of polycarbonate system in various climates.

\begin{tabular}{|c|l|c|c|c|}
\hline Case & \multicolumn{1}{|c|}{ Design } & $\begin{array}{c}\text { Wash., } \\
\text { DC }\end{array}$ & Moscow & Dubai \\
\hline 1 & $\begin{array}{l}\text { Structural Envelope/ Roof - } \\
\text { Zero Gap at Base }\end{array}$ & $3.56 \%$ & $4.7 \%$ & $-1.47 \%$ \\
\hline
\end{tabular}

Table 3: Predicted reduction in total building annual HVAC energy consumption from installation of polycarbonate system in various climates.

\begin{tabular}{|c|l|c|c|c|}
\hline Case & & $\begin{array}{c}\text { Wash., } \\
\text { DC }\end{array}$ & Moscow & Dubai \\
\hline $1 \quad \begin{array}{l}\text { Structural Envelope/ Roof - } \\
\text { Zero Gap at Base }\end{array}$ & $7.3 \%$ & $7.78 \%$ & $-3 \%$ * \\
\hline *Active venting can be used to reduce or eliminate deficit & & & \\
\hline
\end{tabular}

Comparing building energy consumption specific to heating and cooling (HVAC) energy, nearly an $8 \%$ savings is expected in mild to cold climates, and a $-3 \%$ savings in hot climates. In hot climates, active venting systems can be used to reduce or eliminate the negative savings.

\section{Conclusions}

Extensive design work, shock-tube and open-arena testing have been conducted to advance a polycarbonate-based blast mitigating system for building protection. The protective system has been shown to greatly exceed known standards for critical building protection while at the same time providing a lower cost solution compared to relocation or re-building, as well as potentially lower building energy consumption depending on location. While not every building type is a candidate for this system, additional work in the area of high energy absorbing elements to dampen system loads into the building, has been on-going. Ballistics resistance, forced-entry, and severe storm protection are also benefits of the system as well as a reduction of energy consumption in mild and cold climates.

\section{References}

[1] Kenady, J., Barker, D., Lorenzo, J., Pyles, R. "Prediction of Pressure Rise Behind a Shield Wall”, 2010 